\title{
Cuidadores domiciliares: uma demanda para a ação profissional dos assistentes sociais
}

Home caregivers: a demand for action of professional social workers

\author{
Vini Rabassa Silva* \\ Lenara Lamas Stelmake**
}

\begin{abstract}
Resumo:
Este trabalho problematiza as mudanças provocadas pelo Programa de Cuidado Domiciliar no Brasil, com especial atenção no cuidador, buscando evidenciar que as repercussões produzidas em sua vida podem gerar um adoecimento agravado pela desassistência. Destaca, ainda, a necessidade de os cuidadores receberem um acompanhamento profissional, indicando algumas propostas para a ação profissional dos assistentes sociais.
\end{abstract}

Palavras-chave: Cuidado domiciliar. Família. Desassistência ao cuidador. Ação profissional do assistente social.

\begin{abstract}
:
This paper discusses the changes caused by the Home Care Program in Brazil, with special attention on the caregiver, and seeks to show that the effects produced in his life can cause a disease aggravated by the lack of assistance. It also highlights the need of caregivers to receive a professional monitoring, pointing out some proposals for the social workers' professional action.
\end{abstract}

Keywords: Home care. Family. Lack of assistance to the caregiver. Social worker's professional action.

\section{Introdução}

O Programa de Cuidado Domiciliar, instituído no Brasil através da Lei no 10.424 de abril de 2002 (BRASIL, 2002), tem sido apresentado como benéfico para a saúde da população, considerando os benefícios da des-hospitalização (menos risco de aquisição de doenças infectocontagiosas, humanização do tratamento com o convívio familiar, redução de custos, liberação de leitos hospitalares). Entretanto, este Programa supõe a existência de um cuidador, que pode ser um vizinho, um amigo ou alguém contratado,

\footnotetext{
* Doutora em Serviço Social pela Pontifícia Universidade Católica do Rio Grande do Sul, Professora Adjunta do Mestrado em Política Social da Universidade Católica de Pelotas. E-mail: mps@ucpel.tche.br.

** Assistente Social da Universidade Federal de Pelotas, mestre em Política Social pela Universidade Católica de Pelotas. E-mail: lenarastelmach@gmail.com.
} 
sendo o mais comum é que este pertença ao núcleo familiar, quer por razões afetivas, quer por dificuldades financeiras em remunerá-lo.

De fato, devido às suas limitações físicas, as pessoas incluídas no referido programa necessitam que a execução de atividades pessoais, como a higienização, a medicação e a alimentação, dependa da disponibilidade e da boa vontade de terceiros, geralmente familiares, sem formação técnica para a realização de atividades muitas vezes complexas, como o manuseio de equipamentos ou assepsia de ferimentos.

É comum, inclusive, que haja necessidade do apoio da comunidade para suprir necessidades, sobretudo daqueles mais pobres, já que deve haver preparação da casa e do ambiente físico e familiar para o enfrentamento de uma nova situação delicada (SODRÉ, 2005), que irá requerer cuidado especial.

Em decorrência disso, o cuidador torna-se a pessoa-chave e imprescindível no Programa de Cuidado Domiciliar, tanto pela responsabilidade no cuidar como por fomentar a relação entre equipes de saúde e paciente, na qual acontece uma transferência de responsabilidades: uma parte do cuidado passa da instituição de saúde para a família ou cuidador (FEUERWERKER; MERTHY, 2008).

Em comunidades pobres ou de classe média baixa, onde há cuidadores domiciliares, observa-se que o cuidador geralmente não recebe a devida atenção e que muitas vezes, exatamente por exercer esta função, acaba adoecendo. Por isso, este trabalho quer provocar uma reflexão sobre essas pessoas, alertando não só à importância de seu trabalho, mas às consequências que ele produz, e à necessidade de um acompanhamento profissional ao cuidador, que contemple orientações, estratégias facilitadoras e apoio profissional para o desempenho de sua função.

\section{Considerações gerais sobre o Programa de Cuidado Domiciliar no Brasil}

Embora seja uma palavra masculina, quem promove o cuidado, na maioria dos casos, são as mulheres, por meio de muitos pequenos atos, sem remuneração e sem reconhecimento social. Lembrando o que analisa Mioto (2008), os serviços se organizam por meio de uma perspectiva calcada em papéis típicos da família, colocando a mulher como responsável pelo cuidado e pela educação dos filhos. 
No cuidado, são colocados sentimentos, ações, tempo e vida. Segundo Aguirre (2007, p. 192.) “[...] el cuidado está inmerso en la lógica del sacrificio, sacrificio que puede entrañar- sin pretenderlo - un grado de reconocimiento social, [...] y termine por "robarle" el tiempo a quien lo prodiga." ${ }^{1}$

Além dos determinantes socioculturais, é importante destacar que o exercício do cuidado domiciliar está inserido em um contexto socioeconômico que produz determinações sobre o cotidiano do cuidador. Absorvidas na função de cuidadores, essas pessoas muitas vezes passam a ser consideradas, pela própria família, pelas equipes de saúde e pelo doente como alguém que existe para o outro, fazendo com que eles considerem natural não ter mais tempo para cuidarem de si e, muitas vezes, nem percebam que estão adoecendo.

Percebe-se que muitos dos cuidadores pertencentes à classe média baixa e à classe baixa são pessoas solitárias, tristes, sobrecarregadas, sem apoio familiar e que, além das tarefas específicas do cuidado domiciliar, necessitam lidar com sérias dificuldades financeiras, decorrentes do adoecimento da pessoa sob seus cuidados. E até mesmo para quem atribuiu a tarefa de cuidar - familiares e equipe de saúde - geralmente a pessoa do cuidador é esquecida, sendo visualizado apenas o seu trabalho.

Nesse sentido, entende-se que o Programa de Cuidado Domiciliar necessita ser olhado pelo outro lado, isto é, pela ótica do cuidador, daquela pessoa chamada a cumprir funções que eram antes atribuídas a instituições especializadas em cuidar da saúde.

Assumir em casa o papel de cuidador familiar já faz parte da rotina de muitas famílias brasileiras. Assume-se por escolha ou por falta desta, por obrigação ou por gratidão, por amor ou por culpa, "por um querer explicável ou por um não querer sem explicação." (ANDRADE, 2007, p. 100). Os sujeitos, doente, cuidador e família, dependem uns dos outros para que haja uma relação saudável no cuidado domiciliar, nem sempre tranquila, mas necessária: o papel de cada um interfere e complementa o do outro nessa relação cheia de contradições.

\footnotetext{
1 “[...] o cuidado está imerso na lógica do sacrifício, sacrifício que pode entranhar - sem pretendê-lo - um grau de reconhecimento social, [...] e termine por 'roubar-lhe' o tempo a quem o exerce." (tradução nossa).
} 
Assim, refletir sobre o cuidador supõe considerar essas relações entre o doente e a família, pois somente dentro desse contexto é possível buscar a compreensão das consequências do cuidado no cuidador.

A história do cuidador geralmente é rica de detalhes e particularidades: pelo movimento do cuidar e da vida e pelo processo social desenvolvido no cuidado domiciliar, que pode ser percebido por meio de seus gestos, de suas falas, geralmente carregadas de angústias, emoções e medos. Cada pessoa acaba construindo o seu trabalho de cuidador, o qual é construído e reconstruído no desenvolvimento de sua atividade dentro do próprio domicílio. A sua história, as condições subjetivas e objetivas, que interferem no exercício de seu trabalho, e consequentemente na relação com a pessoa enferma, são elementos determinantes na ação do cuidado. Sendo assim, cabe ressaltar que, embora se reconheça que todos os cuidadores têm muita coisa em comum, a reflexão deste trabalho está diretamente dirigida aos cuidadores que vivem em situação de pobreza, que possuem vínculo com Unidades Básicas de Saúde, situadas em territórios considerados de vulnerabilidade social.

Desse modo, apesar de se entender que as necessidades e interesses gerados pelo cuidado domiciliar no cuidador são múltiplos e decorrentes, também, de um contexto social mais amplo, por outro lado se entende que há um conjunto desses interesses e necessidades - companhia, afeto, divisão de responsabilidade, refúgio, espiritualidade, recursos financeiros para suprir as carências trazidas pela doença para dentro do domicílio, além de orientação e apoio para lidar adequadamente com o doente e com o entorno criado pela doença - que sempre perpassam, ainda que variando de intensidade, o trabalho do cuidador. Entretanto, estes elementos geralmente não são percebidos e nem atendidos pelas equipes das Unidades Básicas de Saúde (UBS's) existentes no território de localização do domicílio do enfermo, as quais são consideradas como o serviço de referência do Programa.

Interessante observar que as UBS's geralmente são identificadas com o serviço prestado pelo Estado por meio dos participantes do Programa de Cuidado Domiciliar e, por isso, elas se tornam o local de expressão de descontentamento em relação a tudo que falta em casa para que o doente possa ser atendido de forma adequada. Nessa perspectiva, convém destacar a orientação advinda do próprio SUS, analisada por Pires 
(2000, p. 15): “[...] a partir da atenção básica, o Sistema Único de Saúde quer o reordenamento do modelo de atenção à saúde. Este programa entende a família 'como o espaço nuclear de agregação das pessoas, inseridas em um contexto social, devendo ser objeto prioritário à saúde'"”.

Desta forma, o trabalho na UBS deve ser norteado por uma lógica que permita a construção, no cotidiano, de vínculos conforme as necessidades individuais e coletivas da população, com equipes trabalhando a interdisciplinaridade, o conceito ampliado de saúde e incorporando ferramentas e conceitos das ciências sociais (CAMPOS, 2005), para atenderem efetivamente as reais necessidades de saúde da população. Conforme discorre Nunes (1994, p. 20):

[...] fundamentando-se na interdisciplinaridade como possibilitadora de um conhecimento ampliado de saúde e na multiprofissionalidade como forma de enfrentar a diversidade interna ao saber/fazer das práticas sanitárias. A saúde coletiva constituída nos limites do biológico e do social continua a ter pela frente a tarefa de investigar, compreender e interpretar os determinantes da produção social das doenças e da organização social dos serviços de saúde, tanto no plano diacrônico quanto no sincrônico da história. A saúde coletiva, ao introduzir as ciências humanas no campo da saúde, reestrutura as coordenadas deste campo, trazendo para seu interior as dimensões simbólica, ética e política.

Portanto, o trabalho de toda a equipe profissional da UBS deve considerar os determinantes sociais do contexto desta, e das famílias residentes naquele território, para conseguir compreender as dificuldades enfrentadas pelos cuidadores domiciliares e comprometer-se coletivamente com o atendimento de suas demandas, incluindo o acompanhamento in loco do trabalho realizado, a fim de que seja superada a concepção de repasse total do cuidado a ser dispensado pela equipe da UBS para o cuidador familiar.

Em UBS's Escola, isto é, vinculadas às Faculdades de Medicina, a relação com os cuidadores tem algumas particularidades. Pelo fato de elas visarem também à formação profissional de estudantes de várias disciplinas, dentre elas a medicina, os alunos fazem atendimentos domiciliares, devendo ser realizados em conjunto com a preceptoria. Entretanto, quando o aluno vai ao domicílio, nem sempre é acompanhado pelo preceptor. Nesse caso, ele atende e retorna à UBS para obter a orientação e dar retorno à família. Isso demanda tempo e conhecimento prévio do caso, o que gera frustração nos 
cuidadores por não obterem uma resposta imediata, além da preocupação em saber se as necessidades do enfermo serão interpretadas corretamente quando levadas ao responsável pelo tratamento. Cabe ressaltar que em ocasiões de emergência e urgência, é acionado imediatamente o serviço de atendimento móvel do município.

A rotatividade de alunos também ocasiona um atendimento fracionado, já que cada novo aluno ao chegar desconhece a realidade, o contexto em que a doença se desenvolveu e como determinada família foi-se constituindo para o cuidar. Isso dificulta o trabalho, pois como afirma Campos (2005), os trabalhadores de saúde, para lidarem com o processo saúde e doença, precisam incorporar o social e o subjetivo. Assim, para o estágio ser um momento rico na formação dos estudantes, é imprescindível um acompanhamento direto do estagiário pelo profissional.

Outro problema geralmente enfrentado nas UBS's, em geral, é o reduzido tempo dos profissionais para o atendimento da demanda, o que contribui para que sejam priorizados os atendimentos que são feitos diretamente na UBS, ficando a visita domiciliar em segundo plano. Por isso, é frequente a queixa dos cuidadores sobre a falta de visita domiciliar para acompanhamento do enfermo. Conforme analisa Mendes: “[...] os serviços de atendimento domiciliar na rede de saúde pública são pouco significativo, pontuais e fragmentados." (MENDES, 2002, p. 30).

Assim, é preciso ter presente que este Programa de Cuidado Domiciliar está inserido em um contexto em que as condições de trabalho e os recursos disponibilizados pelo SUS são insuficientes e ineficazes, levando à baixa resolutividade dos problemas e aumentando o desgaste dos profissionais que tentam construir saúde.

Há falta de uma atenção especial por parte da própria política de saúde, nesse caso representada pelas UBS's, a qual, em última instância, é a responsável pela efetivação do Programa de Cuidado Domiciliar. Dessa forma, a política de saúde repassa uma responsabilidade ao cuidador sem prever nem oferecer o suporte necessário às repercussões que este repasse irá desencadear nas pessoas que assumirem tal responsabilidade, isto é, nos "cuidadores". A escuta a essas pessoas muitas vezes desvela sentimentos inesperados, emergidos pelo choro, pelo silêncio, pelo tom convicto na voz e pelas expressões do corpo. E, não raro, revela alguém em quem o simples fato de 
encontrar outra pessoa disposta a ouvi-lo provoca lágrimas de alívio e expressões de agradecimento.

A partir dessas considerações, reitera-se o fato de o cuidador ter sido encarregado de desempenhar uma árdua função sem que esteja previsto um tipo de assistência para o seu desenvolvimento. Por isso, sem negar alguns benefícios que o Programa de Cuidado Domiciliar pode trazer ao enfermo e aos familiares, o que se deseja, aqui, é trazer presente a necessidade de uma atenção especial aos cuidadores.

Essa é uma questão que precisa ser discutida e repensada dentro do Programa de Cuidado Domiciliar, como uma resposta específica da Política de Saúde de forma intersetorial com outras políticas que atuam no mesmo território do domicílio do enfermo.

A internação domiciliar cria uma situação diferente dentro do domicílio, a qual, dependendo da complexidade da doença, pode ser mais ou menos complicada para os familiares. Há casos que exigem adaptações na residência para instalação de aparelhos, outros requerem um espaço mais reservado ao enfermo para a sua higienização e, ainda, outros que não requerem mudanças de estrutura física, mas que certamente exigem uma nova postura por parte dos familiares para assegurarem um bem-estar ao enfermo sem criar um mal-estar exagerado aos demais residentes naquele domicílio. Nas famílias mais pobres, a situação tende a ser mais difícil, considerando que qualquer acréscimo de despesa já será penoso e que as residências geralmente não possuem espaço suficiente para um bem-estar adequado ao número de residentes.

Nesses casos, às vezes, orientações de trabalhadores da área da saúde podem contribuir para melhor equacionar problemas com adaptações no ambiente físico, a fim de facilitar o cuidado e proporcionar melhores condições ao doente. Entretanto, é necessário que sejam observadas as possibilidades e os limites existentes e respeitadas as crenças, cultura e lembranças, às vezes expressas em objetos e paredes cheios de significados para os moradores daquele domicílio, a fim de evitar mais estresse e angústia. Esse fato é importante, visto que o espaço físico pode ou não ajudar no cuidado, seja para tratar o doente ou para trazer a todos um melhor bem-estar. O domicílio é um local que, a priori, é de todos, mas o cuidado domiciliar, na maioria das vezes, leva a família a priorizar a pessoa e suas necessidades para realização do tratamento. Assim, 
tornar o espaço menos centrado na doença, sempre que for possível, auxilia a todos, inclusive ao cuidador e ao doente.

É importante que os profissionais que trabalham em UBS's considerem sempre que:

\begin{abstract}
Atender em domicílio, portanto, não significa tornar público o espaço que é privado, mas sim particularizar uma ação. Não significa "levar o hospital para a casa do cliente", mas sim, conhecendo o "território" do indivíduo e respeitando suas particularidades, conseguir traçar um plano de cuidados de acordo com as possibilidades e limites aí reconhecidos (ANDRADE, 2007, p.156).
\end{abstract}

\title{
Demandas dos cuidadores para os assistentes sociais e propostas para atuação
}

O Programa de Cuidado domiciliar exige a "construção de modelos onde as condutas dos profissionais envolvidos, [...], sejam não somente corretas do ponto de vista técnico (imprescindíveis), mas também amorosas e empáticas" (FLORIANI; SCHRAMM, 2004). No entanto, além dos fatores decorrentes da própria Política da Saúde, conforme comentado anteriormente, a falta de tempo, de compromisso profissional, ou de uma melhor formação, nem sempre viabiliza este tipo de ação profissional. Dessa forma, a engrenagem do sistema trabalha contra o atendimento requerido pelo Programa de Cuidado Domiciliar. A burocracia, o despreparo de muitos profissionais, a falta de publicização de direitos e de como acessá-los contribuem para que não seja dada, no momento certo, as respostas de que o cuidador necessita, sejam elas relacionadas a recursos materiais, medicação, conhecimento ou apoio pessoal.

O cuidador acaba sendo alguém partícipe da função que o Estado deveria desempenhar, mas sem recursos, rede de apoio e Política de Saúde que efetive o cuidado domiciliar, o cuidador não tem sustentação.

Diante disso, o Programa de Cuidado Domiciliar suscita a questão: quem "cuida" do cuidador? Aqui, o "cuidar" está sendo entendido como intervenção, articulação em uma sociedade formada, simultaneamente, "por momentos de estrutura e momentos de ação" (COUTINHO, 1990, p. 27).

$\mathrm{Na}$ sociedade atual, em que as estruturas e o funcionamento das políticas sociais estão comprometidas pela falta de investimento financeiro, tanto na provisão de recursos materiais como de recursos humanos qualificados, entendemos que o Assistente Social é 
um dos profissionais que pode contribuir diretamente com esse Programa de Cuidado Domiciliar sem messianismo e renunciando ao fatalismo.

Nesse sentido, o envolvimento e a participação direta destes profissionais em movimentos, conselhos e outras organizações que lutem por uma política de saúde de resolutividade, bem como o seu incentivo para que a população se organize e busque os seus direitos, é fundamental.

O Assistente Social pode, ainda, atuar no cotidiano da equipe de saúde, trazendo para discussão a realidade particular do cuidador, que geralmente é invisível para muitos, e provocar a descoberta e a implantação, pela UBS, de alternativas viáveis que possam facilitar o cuidado. Desse modo, cabe ao assistente social destacar a necessidade da adoção dos determinantes sociais como estruturantes dos processos saúde-doença (NOGUEIRA; MIOTO, 2008), alertando para o risco de adoecimento do cuidador, exatamente pelo exercício do cuidado dispensado ao enfermo.

Esse profissional pode, ainda, usar o seu instrumental técnico-operativo para: 1intervir diretamente com o fornecimento de informações úteis ao cuidador; 2-favorecer a articulação da rede para o atendimento não só do doente, mas dos familiares e especialmente do cuidador; 3- acompanhar e apoiar a família, dando especial atenção ao cuidador, pela escuta sensível e busca da garantia de acesso aos direitos preconizados ao doente.

A partir desta postura, ele poderá construir um trabalho em conjunto no cuidado domiciliar, oportunizando a vivência de trabalho em equipe interdisciplinar no campo de conhecimento da saúde coletiva. Como sublinha Merhy (1997, p. 72):

\footnotetext{
Nestes muitos anos de militância e acumulação de experiências vivenciadas na busca da mudança do modo de produzir saúde no Brasil, aprendemos que: ou esta é uma tarefa coletiva do conjunto dos trabalhadores de saúde, no sentido de modificar o cotidiano do seu modo de operar o trabalho no interior dos serviços de saúde, ou os enormes esforços de reformas macro-estruturais e organizacionais, nas quais nos temos metido, não servirão para quase nada.
}

Essa perspectiva possibilita superar a suposta dissonância existente entre a prática dos assistentes sociais e o projeto ético-político da profissão, entre a teoria e a prática e entre a intenção e a ação. 
Muitas são as exigências feitas ao cuidador, desde a entrega, doação, renúncia de suas atividades pessoais, administração de um orçamento que se já era difícil antes da doença, até o desenvolvimento de habilidades nunca exercidas antes, como ter que manusear aparelhos médicos, os quais o paciente usa no domicílio. O somatório de exigências pode ocasionar stress, adoecimento e conflitos familiares.

O assistente social pode ser aquele que, como membro da equipe de saúde da UBS, assume o papel principal de "cuidar do cuidador". Para tanto, deverá facilitar a compreensão da equipe sobre o cuidador, esclarecendo sempre que necessário sobre a situação vivenciada por ele, em seu cotidiano familiar, de forma objetiva e simples e instigar para que os outros profissionais procurem facilitar a lida do cuidador.

Além disso, será muito importante manter um vínculo sistemático com o cuidador, tanto para facilitar a sua relação com os demais da equipe, como para escutá-lo, apoiá-lo e incentivá-lo a descobrir formas e meios de tornar a sua função mais fácil de ser desempenhada e menos desgastante.

Assim, o assistente social pode ser o mediador entre a equipe médica e o cuidador, sem excluir a necessidade do contato direto entre ambos. Porém, ele pode ser a presença mais assídua, o tradutor de algumas linguagens técnicas, o mais habilidoso no acolhimento, incluindo a escuta e o apoio sempre atento às questões éticas e legais que devem nortear o seu trabalho, bem como delimitar o seu trabalho profissional.

Para que isso se efetive, é importante que o assistente perceba e interprete criticamente a realidade socioeconômica das famílias que recorrem às UBS's. Muitas delas sem o mínimo de condição socioeconômica, física e emocional para oferecerem um cuidado domiciliar, o que se torna "mais uma carga". E perversamente o trabalho dessas famílias, para acessarem serviços, torna-se mais difícil, já que as diferenças fazem com que as possibilidades de usufruírem dos serviços também sejam desiguais. São burocracias que precisam ser enfrentadas; exames e tratamentos que requerem longos deslocamentos de quem não tem meios para pagar transporte; tempo de dedicação exclusiva de quem precisa trabalhar em tempo integral; cuidados de higienização de quem não tem casa com condições sanitárias adequadas entre outras dificuldades. Muitas dessas situações fogem do idealizado pela maioria dos membros da equipe de saúde, logo a interpretação do assistente social é fundamental, para que a equipe consiga 
desenvolver o programa dentro das condições reais dos usuários e assuma com eles a luta pelas condições necessárias a um tratamento fora do hospital.

Muitas vezes isso implica algo simples, como facilitar o acesso à UBS, para que os cuidadores possam discutir com a equipe os problemas do doente, ou para que solicitem um atendimento em casa para este, ou ainda, para que recebam atendimento pessoal, sem que tenham que enfrentar filas e longas esperas, já que não podem se afastar por muito tempo de casa. Esses procedimentos, embora simples, não são realizados na maioria das UBS's, que tratam o caso de forma isolada e ainda atribuem especificamente a um profissional esse encargo. Esse fato demonstra que o programa não é desenvolvido como sendo da equipe da UBS, mas, sim, de alguns profissionais que se comprometem com este. E, ainda, que repassa só a responsabilidade para o domicílio, sem integrá-lo como objeto de atenção.

A intervenção profissional pode ser definitiva quanto à continuidade do cuidado domiciliar. É possível afirmar que uma relação mais acolhedora, para além do meramente estabelecido como norma, poderá amenizar e em certos casos resolver parte de um grande problema do cuidador. Assim, se o cuidar no domicílio depende da boa vontade e autonomia profissional, isso necessita ser superado por uma obrigação coletiva da equipe de saúde.

E mais ainda, tanto o trabalho de facilitar o acesso da família a recursos e serviços públicos de que necessita, como o de obter apoio aos familiares e, em especial ao trabalho do cuidador, são fatores determinantes da importância do trabalho da UBS ser articulado com a rede de serviços existente no território, dentre eles o Centro de Referência de Assistência Social - CRAS. O assistente social do CRAS poderá contribuir para ao acesso a outros serviços públicos e à mobilização das pessoas de grupos de convivência a prestarem apoio à família, que às vezes também sofre com o estigma da "família do doente", facilitando o alívio de tensão, e intervindo no isolamento a que também fica submetido o cuidador.

Enfim, para uma resolutividade dos problemas no cuidado domiciliar é necessário que o assistente social participe efetivamente do processo terapêutico proposto, rejeitando ser solicitado só para executar atividades já planejadas ou para "apagar o 
fogo", sendo mero tarefeiro das decisões de outros profissionais, que na maioria das vezes têm dificuldades de enxergar o social.

Para tanto, no processo de cuidado domiciliar, o assistente social deve participar desde o planejamento, possibilitando imprimir alterações concretas e visíveis na realidade, dando um contorno definido e identificável à sua ação profissional (NOGUEIRA; MIOTO, 2008, p. 274), e também às suas ações dentro do processo terapêutico do cuidado domiciliar. Assim como propor ou favorecer, quando já existente, a avaliação periódica do programa e de cada caso em atendimento, por meio de reuniões semanais de equipe para essa discussão, a qual poderá ser aberta à participação de representantes da rede de serviços existente na comunidade. Essas avaliações são a forma de verificar a eficácia do atendimento, podendo apontar para a necessidade de buscar novas estratégias que possibilitem um melhor atendimento. É importante, inclusive, contribuir para que a equipe supere a ideia de que "reunião é perda de tempo", comumente encontrada dentro do modelo biocêntrico.

A fim de obter os subsídios de enfrentamento da realidade e dos obstáculos presentes nas equipes do cuidado domiciliar, o assistente social necessita desenvolver processos investigativos que ultrapassem os limites da proteção da UBS, para que se possa constituir em uma fonte de conhecimentos e de participação em todo o processo. Conforme analisa lamamoto (2008, p. 428):

\footnotetext{
De um lado a atuação do assistente social pode representar uma "invasão de privacidade" através de condutas autoritárias e burocráticas, como extensão do braço coercitivo do Estado (ou da empresa). De outro lado, ao desvelar a vida dos indivíduos, pode, em contrapartida abrir possibilidades para o acesso das famílias a recursos e serviços, além de acumular um conjunto de informações sobre as expressões contemporâneas da questão social pela via do estudo social.
}

Esse é um viés que exige muita atenção e que revela a contradição do cuidado no domicílio. O profissional, ao entrar em um domicílio, necessita reconhecer o espaço domiciliar como íntimo, captar o significado da doença para a família, as condições de moradia e a organização da família, suas crenças e cultura. Entretanto, nunca poderá deixar de informar quais os melhores procedimentos e atitudes a tomar em determinadas situações de forma clara e acessível às condições da família. 
Entendemos que o apoio ao cuidador é indiscutível como parte do trabalho do assistente social, incluindo a orientação sobre o acesso aos seus direitos previdenciários e assistenciais. É preciso, também, ter claro que a situação de cuidado no domicílio não deve nunca ser imposta, nem ao cuidador, nem ao doente, evitando que esse atendimento torne-se "uma violência para paciente e família, e, a nosso ver, uma irresponsabilidade da equipe" (ANDRADE, 2007, p. 96).

O profissional deverá entender os significados da doença e as mudanças ocasionadas nas famílias para realizar a melhor forma de intervenção. Mesmo que tudo tenha sido explicado de forma simples e de fácil entendimento, deverá deixar claro ao cuidador como proceder em finais de semana e à noite quando precisarem de atendimento, informando inclusive telefones de urgência e sobre questões de ordem burocráticas, que trazem transtornos quando não encaminhadas corretamente.

Além disso, é conveniente ter noção que pode ocorrer o óbito, uma dor que prevalece a qualquer orientação, mas que evitará maiores agonias se o cuidador estiver informado sobre as medidas a tomar. O óbito não encerrará o cuidado domiciliar, pois o cuidador terá ainda que receber atendimento, seja clínico, psicológico, judicial ou social. Muitos ficam descobertos pela previdência social, pois recebem o Benefício Assistencial do doente, benefício que se extingue com o óbito. A divisão de bens ou a falta deles e irregularidades legais em documentações e imóveis merecem apoio e orientação sobre a melhor forma de resolver os problemas, uma vez que o cuidador já estará bastante desgastado pelo cuidado. Nesse sentido, será muito importante verificar como se encontra a família, os adoecimentos, e como a UBS poderá tratar ou encaminhar estas consequências na vida familiar. A visita após o óbito, se possível, deverá ser realizada por um membro da equipe que atendeu aquele caso.

Uma contribuição importante que pode reduzir malefícios do PCD nos cuidadores, e que pode ser dada pelo assistente social, é a organização de grupo de cuidadores. Ter um grupo de apoio poderá fortalecer os cuidadores, aliviando seu stress, ao receberem ajuda de pessoas que enfrentam situações semelhantes e, ainda, ao lhes facilitarem o acesso a informações úteis para a sua função.

Outra contribuição que o assistente social pode oferecer é a de incentivar para que, quando possível, os cuidadores, ou outro familiar, participem dos conselhos locais de 
saúde, bem como incluir na pauta a discussão do cuidado domiciliar, inclusive as necessidades dos cuidadores, para que no exercício do controle social essas questões ganhem visibilidade maior. Essa pode ser uma estratégia para, ainda, diminuir o risco de esse ser um programa comprometido apenas com a diminuição de custos da internação hospitalar (STELMAKE; SILVA, 2009).

E, finalmente, o assistente social poderá incentivar a realização de pesquisas sobre o programa contribuindo para dar maior visibilidade a este no que tange às contradições que o perpassam.

\section{Considerações Finais}

O cuidado domiciliar acarreta, no cuidador, um enorme desgaste, considerando o fato de ele não poder contar com uma Política de Saúde que atenda às suas necessidades e as do doente.

A doença interfere no bem-estar familiar, pois há um direcionamento para ela. A rotina é transformada e, não raro, o cuidado provoca estremecimento das relações devido ao fato de nem todos os membros da família aceitarem a nova roupagem familiar e à queda de atenção e afetos. Altera-se a relação do cuidador com a família, sendo que muitas vezes ele sentir-se-á só, com medo, triste pelo familiar doente, cheio de dúvidas e incertezas, tentando fazer o melhor. Do mesmo modo, muitas vezes o cuidador sofre pressão por parte da família, que deveria dividir as tarefas com ele, quando ela o vê como único responsável e como aquela pessoa com disponibilidade infinita e tolerância permanente. Não é considerado como sujeito com vida própria, escolhas e desejos. É como se a sua identidade fosse totalmente absorvida pela função de cuidador.

Os familiares entendem o cuidador, no exercício de cuidar como se fosse um sacerdote ortodoxo, e assim o tratam. Na verdade, é o depositário de todos os anseios e as responsabilidades dos demais, tendo, muitas vezes, de prestar contas do ato de cuidar. Às vezes, inclusive, isso mascara o sentimento de culpa da família como um todo em relação ao doente. Assim, o abandono por parte dos familiares e da rede de proteção social (saúde, assistência e previdência) torna o cuidador cada vez mais fragilizado na tarefa de cuidar. 
Contudo, nem só as relações pessoais são atingidas. O orçamento doméstico sofre cortes, pois a doença determina prioridades. Surgem novas despesas com medicações, alimentação ou até mesmo com aparelhos para o doente. Nem sempre existem os recursos disponíveis, o que torna básica a ajuda financeira de terceiros, o que leva a um endividamento que sobrecarrega ainda mais o cuidador, já que a luta para conseguir o necessário, por meio de subsídios governamentais, raramente é vitoriosa e em tempo hábil.

O bem-estar do ambiente físico da moradia também é afetado e, por vezes, totalmente anulado, principalmente nas famílias de baixa renda, cuja casa é modesta. 0 espaço já reduzido para uma família, com a doença, é ainda mais dividido, ficando desconfortável. A enfermidade é visualizada o tempo todo e o sofrimento exposto. A ausência de condições econômicas também impede o oferecimento de um mínimo de bem-estar ao doente, como um quarto privativo, cama adequada, temperatura agradável, meios para melhor se movimentar, alimentação saudável, material de higiene adequado, o que acaba agravando as dificuldades do cuidador no exercício de suas atividades.

Portanto, o SUS, responsável pela proteção dos usuários, no Programa de Cuidado Domiciliar, está falhando duplamente: por não oferecer as condições necessárias ao tratamento integral do doente e por ser omisso na atenção ao cuidador. Não há uma Política de Saúde efetiva e legítima, isto é, que proteja os sujeitos, cuidadores, para que possam enfrentar, de forma sadia, ainda que com sofrimento, as múltiplas consequências geradas pelo cuidado domiciliar.

Enfim, este é um Programa da Política da Saúde que exige o compromisso éticopolítico do Assistente Social no dia a dia da profissão, capaz de animar outros profissionais a se comprometerem com o seu desenvolvimento de forma eficaz, o que exige cuidar do cuidador.

E o "cuidar do cuidador" é uma contribuição que o assistente social pode oferecer particularmente nas UBS's, por meio de uma postura profissional ético-política e de uma ação investigativa e interventiva de natureza interdisciplinar e intersetorial. Ele pode dar visibilidade a um trabalho penoso e não reconhecido no nosso país pela divisão sociotécnica do trabalho, alertando a sociedade à possibilidade de exploração realizada 
pelo Estado ao repassar obrigações às famílias em nome de uma humanização que desonera os cofres públicos, não só pela des-hospitalização, mas pelo abandono do atendimento necessário.

\section{Referências}

AGUIRRE, R. Los cuidados familiares como problema público y objeto de políticas. In: . Familias y políticas públicas en América Latina: una historia de desencuentros. Santiago de Chile: Publicación de las Naciones Unidas, 2007. p. 187-199.

ANDRADE, L. Desvelos: trajetórias no limiar da vida e da morte - cuidados paliativos na assistência domiciliar. 2007. Tese (Doutorado em Serviço Social) - Pontifícia Universidade Católica de São Paulo, São Paulo. 2007.

BRASIL. Lei no 10. 424 de 16 de abril de 2002. Acrescenta capítulo e artigo à Lei no 8.080, de 19 de setembro de 1990, que dispõe sobre as condições para a promoção, proteção e recuperação da saúde, a organização e o funcionamento de serviços correspondentes e dá outras providências, regulamentando a assistência domiciliar no Sistema Único de Saúde. Disponível em: <http://portal.saude.gov.br/>. Acesso em: 10 jul. 2009.

CAMPOS, G. W. S. Diretrizes pra o ensino médico na rede básica de saúde. Documento Preliminar, abril 2005. mimeo.

COUTINHO, C. N. Gramsci e as ciências sociais. Serviço Social e Sociedade, São Paulo, ano 11, n. 34, p. 21-40, dez. 1990.

FEUERWERKER, L. C. M.; MERTHY, E. E. A contribuição da atenção domiciliar para a configuração de redes substitutivas de saúde: desinstitucionalização e transformação de práticas. 2008. Disponível em: <www.scielosp.org/revistas/rpsp>. Acesso em: 18 jul. 2009.

FLORIANI, C. A.; SCHRAMM, F. R. Atendimento ao idoso: problema ou solução? Caderno de Saúde Pública, Rio de Janeiro, v. 20, n. 4, jul./ago. 2004.

IAMAMOTO, M. V. Serviço Social em tempo de capital fetiche: capital financeiro, trabalho e questão social. 2. ed. São Paulo: Cortez, 2008.

MENDES, P. B. M. T. Quem é o cuidador? In: DIAS, E. L. F. et al. (Org.). Orientações para cuidadores informais na assistência domiciliar. Campinas: Ed. Unicamp, 2002. p. 17-32.

MERHY, E. E. Em busca do tempo perdido: a micropolítica do trabalho vivo em saúde. In: MERHY, E. E.; ONOCKO, R. (Org.). Práxis en salud: un desafio para lo público. São Paulo: Hucitec, 1997. p. 71-112.

MIOTO, R. C. T. Família e políticas sociais. In: BOSCHETTI, I. et al. (Org.). Política social no capitalismo- tendências contemporâneas. São Paulo: Cortez, 2008. p. 130-148. 
NOGUEIRA, V. M. R; MIOTO, C. R. T. Desafios atuais do Sistema Único de Saúde - SUS e as exigências para os Assistentes Sociais. In: MOTA, A. E. et al. Serviço social e saúde. São Paulo: Cortez; Brasília: OPAS, OMS, Ministério da Saúde, 2008. p. 218

NUNES, E. D. Saúde coletiva: história de uma idéia e de um conceito. Saúde e Sociedade, São Paulo, v. 3, n. 2, p. 5-21, 1994.

PIRES, D. E. P. Programa saúde da família: entrevista. Revista Brasileira de Enfermagem, Brasília, v. 53, n. esp., p. 7-16, dez. 2000.

SODRÉ, F. Alta social: a atuação do Serviço Social em cuidados paliativos. Serviço Social e Sociedade, São Paulo, v. 82, 2005.

STELMAKE, L. L; SILVA, V. R. Cuidado domiciliar e controle social. In: CONGRESSO PARANAENSE DE ASSISTENTES SOCIAIS, 4., 2009, Curitiba. Anais... Curitiba, 2009. 